\title{
Analysis and occurrences of methoxylated polybrominated diphenyl ethers and polybrominated diphenyl ethers in channel catfish, crayfish, fish feeds and fishmeal from China
}

\author{
Xiaozhong Hu ${ }^{1}$, , Decong Hu${ }^{1, ~ *, ~ H u i ~ W a n g ~}{ }^{1}$, Wei Chen ${ }^{1}$, Bin $\mathrm{Wu}^{2}$, Changjun $\mathrm{Lin}^{2}$ \\ ${ }^{1}$ Technology Center of Hubei Entry-Exit Inspection and Quarantine Bureau of PRC, Qintai Road 588, Wuhan 430050, China \\ ${ }^{2}$ Technology Center of Liaoning Entry-Exit Inspection and Quarantine Bureau of PRC, Changjiang East Road 60, Dalian 116001, China \\ * Decong Hu and Xiaozhong Hu contribute equally to this work and are both as the first author and corresponding author.
}

\author{
Email address: \\ huxz2002@163.com (Xiaozhong Hu), deconghu_hust@163.com (Decong Hu)
}

\section{To cite this article:}

Xiaozhong Hu, Decong Hu, Hui Wang, Wei Chen, Bin Wu, Changjun Lin. Analysis and Occurrences of Methoxylated Polybrominated Diphenyl Ethers and Polybrominated Diphenyl Ethers in Channel Catfish, Crayfish, Fish Feeds and Fishmeal from China. Science Journal of Analytical Chemistry. Vol. 2, No. 3, 2014, pp. 17-28. doi: 10.11648/j.sjac.20140203.12

\begin{abstract}
PBDEs are widely used brominated flame retardant, which are increasingly reported in the environment. $\mathrm{MeO}-\mathrm{PBDEs}$ are structural analogs to PBDEs, and reported as natural products and novel pollutants present in the environment. Concentrations of thirteen PBDEs and eight MeO-PBDEs in a large number of channel catfish, crayfish, fish feeds and fishmeal collected from Hubei province of China were investigated in this study. A fast isotopic dilution GC-MS method was firstly developed to simultaneously determine thirteen PBDEs and eight MeO-PBDEs in channel catfish, crayfish, fish feeds and fishmeal in this study, and especially for the first time MeO-PBDEs and PBDEs in crayfish, fish feeds and fishmeal. Pressurized liquid extraction and multi-layer silica gel column chromatography cleanup were used, and some important steps and crucial parameters were modified and intensified compared with other literatures. Besides, the conditions of GC and MS were also optimized. The limits of quantitation values of $0.25-5,1-5 \mu \mathrm{g} \mathrm{kg}^{-1} \mathrm{wet}$ weight in channel catfish and crayfish were calculated for PBDEs and MeO-PBDEs, respectively; so did 1-20, 4-20 $\mu \mathrm{g} \mathrm{kg}^{-1}$ wet weight in fish feeds and fishmeal. In addition, good repeatability and accuracy of the whole method were achieved. The established methods were therefore suitable for the simultaneous determinations of thirteen PBDEs and eight MeO-PBDEs in these samples at trace contamination levels. Using the established methods, PBDEs or MeO-PBDEs emerged in 2 of 80 channel catfish, 1 of 80 crayfish, 6 of 60 fish feeds and 4 of 40 fishmeal, and in low- $\mu \mathrm{g} \mathrm{kg}{ }^{-1}$ wet weight for these samples.
\end{abstract}

Keywords: Methoxylated Polybrominated Diphenyl Ethers (MeO-PBDEs), Channel Catfish, Crayfish, Fish Feeds, Fishmeal

\section{Introduction}

Polybrominated diphenyl ethers (PBDEs) are one class of halogenated organic brominated flame retardants (BFRs), and have been used industrially in large volumes for flame protection purposes in various commercial products such as electronic equipment and textiles. The commercial PBDEs products predominantly consist of so-called penta-, octaand decabromodiphenyl ether products. They have been widely distributed in the air, dust, fish and human milk due to their physical, chemical and bio-accumulative characteristics, such as environmental persistence and high lipophilicity [1-8].

Methoxylated polybrominated diphenyl ethers (MeO-PBDEs) are structural analogs to PBDEs, which have been considered synthetic anthropogenic compounds and reported as natural products present in the marine environment. In marine wildlife MeO-PBDEs were first analyzed in the aquatic Baltic environment, e.g., seal and fish from the Baltic Sea in year 1997 [9]. In recent years, MeO-PBDEs have been paid special attention mainly in biotic samples all over the world, and were found in eggs of 
white-tailed sea eagles breeding in different regions of Sweden [10], in fish and shellfish samples from the Mediterranean Sea [11], in mullet (Mugil cephalus) and sea bass (Dicentrarchus labrax) from Bizerte Lagoon, Tunisia [12], in mollusk and fish from the Bohai Sea and the Donghai Sea, China [13], in blue mussels from the Baltic Sea, Sweden [14], in fish from local supermarket in Catalonia, Spain [15], and in Japanese common squid (Todarodes pacificus) from Korean offshore waters [16]. $\mathrm{MeO}-\mathrm{PBDEs}$ are major contributors to the persistent organobromine load in sub-Arctic and Arctic marine mammals, covering a time period of more than 20 years [17].

Following concerns about contamination status of PBDEs and MeO-PBDEs in the environments, have led to the rising concern about the possible adverse health effects to humans. Toxicity studies indicate that the liver, thyroid gland and possibly developmental reproductive organs are particular targets of PBDEs toxicity [18, 19]. Evidence is emerging that PBDEs may be developmental neurotoxicants, as behavioural, neurochemical and hormonal deficits have been found following perinatal exposure [20-25]. PBDEs are capable to induce cell death of cerebellar granule cells in culture [26]. Madia et al reports PBDE-99 can induce apoptosis in astrocytoma cells assessed by the TUNEL method and by Hoechst 33258 staining, via a p53 dependent mechanism [27]. Our study indicates PBDE-209 and PBDE-47 can inhibit the proliferation of Hep G2 cells by inducing apoptosis through ROS or NO generation [28, 29]. A few researches about toxicity of $\mathrm{MeO}-\mathrm{PBDEs}$ indicate the kind of compounds have effects on steroidogenic genes, aromatase activity and steroid hormones in vitro and may have the potential to affect steroidogenesis and reproduction in whole organisms $[30,31]$. To satisfy the requirements of further accurate risk assessments for these chemicals, especially MeO-PBDEs, it is expected that the trend in generating MeO-PBDEs and PBDEs data will be encouraged to grow in environmental and biotic samples.

The Hubei province of China has an old farm and aquaculture production tradition. Especially there are a plenty of channel catfish and crayfish from Hubei exported to other countries. These productions are favorite food for people and their safety has been highly concerned by our previous papers $[32,33]$. Moreover, fish feeds are one kind of farm products, their contaminations have also been concerned in our previous papers [33, 34]. To our knowledge, there is little information about the degree of $\mathrm{MeO}-\mathrm{PBDEs}$ and PBDEs contamination in channel catfish, crayfish, fish feeds and fishmeal from the region in China. In addition, there are only few literatures about simultaneous analysis method and contamination of MeO-PBDEs and PBDEs in fish [11-13, 16-17], especially no literature about analysis method and contamination in crayfish, fish feeds and fishmeal. The analysis of PBDEs and MeO-PBDEs in biological samples is difficult because they are usually present at $\mu \mathrm{g} \mathrm{kg}^{-1}$ levels and the matrices involved are generally complex. Therefore, highly selective and sensitive techniques including sample preparation, cleanup, instrument and quantitative method are required.

Since the two kinds of compounds usually exit in a same environment compartment, the present work describes a simultaneous determinations of thirteen PBDEs and eight MeO-PBDEs in channel catfish, crayfish, fish feeds and fishmeal by isotopic dilution GC-MS which is always more reliable and especially for the first time for simultaneous determinations of MeO-PBDEs and PBDEs in crayfish, fish feeds and fishmeal. In addition, the contamination of $\mathrm{MeO}-\mathrm{PBDEs}$ and PBDEs in these samples matrix from the Hubei province of China was investigated, and the contamination of MeO-PBDEs was more concerned.

\section{Material and Methods}

\subsection{Chemicals and Reagents}

Acetone was supplied from JT Baker (Phillipsburg, USA). Cyclohexane, dichloromethane (DCM) and iso-octane were supplied from $\mathrm{CNW}$ (Germany). Anhydrous sodium sulfate $\left(\mathrm{Na}_{2} \mathrm{SO}_{4}\right)$ (p.a.) was from Sinopharm Chemical Reagent Co., Ltd (Shanghai, China). Florisil was from Sigma-Aldrich Laborchemikalien $\mathrm{GmbH}$ (Seelze, Germany). Silica gel 60 (0.063-0.200 mm, 70-230 mesh ASTM) was from Merck (Darmstadt, Germany).

A standard solution of native MeO-PBDEs containing the congeners 5-MeO-BDE47, 6-MeO-BDE47, 4'-MeO-BDE49, 2'-MeO-BDE68, 5'-MeO-BDE99, 5'-MeO-BDE100, 4'-MeO-BDE101 and 4'-MeO-BDE103, at a concentration of $5 \mu \mathrm{g} \mathrm{mL}^{-1}$ in nonane and toluene $(92: 8)$ was supplied by Wellington Laboratories. A standard solution of native PBDEs containing congeners BDE17, BDE28, BDE47, BDE66, BDE71, BDE85, BDE99, BDE100, BDE138, BDE153, BDE154, BDE183 and BDE190, at $5 \mu \mathrm{g} \mathrm{mL}^{-1}$ of each congener in iso-octane and toluene (97.5:2.5), was also obtained from AccuStandard, Inc. (USA). For quantification by isotope dilution and internal standard, a standard mixture of ${ }^{13} \mathrm{C}_{12}$-labelled PBDEs 28, 47, 99, 100, 154, 153 and 183 (MBDE-MXFS), supplied by Wellington Laboratories, at $2 \mu \mathrm{g} \mathrm{mL}^{-1}$ of each congener in toluene and nonane (74.8:25.2) was used as surrogate internal standard. In addition, a standard mixture of ${ }^{13} \mathrm{C}_{12}$-BDE77 and 138 (MBDE-MXFR) at a concentration of $2 \mu \mathrm{g} \mathrm{mL}^{-1}$ in toluene and nonane (92.8:7.2) (Wellington Laboratories) was used as syringe standard for recovery determination. Mixed series working standards of MeO-PBDEs and PBDEs containing MBDE-MXFS and MBDE-MXFR were prepared by serial dilutions of these stock solutions with iso-octane. The detailed information of these standard substances was presented in table 1. 
Table 1. The information and the ions monitored of thirteen PBDEs, eight MeO-PBDEs, MBDE-MXFS and MBDE-MXFR

\begin{tabular}{|c|c|c|c|c|c|c|}
\hline Br No. & Abbreviation & Molar mass & $\begin{array}{l}\text { Precursor ions, }[\mathrm{M}]^{+} \\
\text {and }[\mathrm{M}+2]^{+} \text {, or } \\
{[\mathrm{M}-2]^{+}(\mathrm{m} / \mathrm{z})}\end{array}$ & $\begin{array}{l}\text { Product ions, } \\
{[\mathrm{M}-2 \mathrm{Br}]^{+} \text {and }[(\mathrm{M}+2)-2 \mathrm{Br}]^{+} \text {, }} \\
\text { or }[(\mathrm{M}-2)-2 \mathrm{Br}]^{+}(\mathrm{m} / \mathrm{z})\end{array}$ & $\begin{array}{l}\text { The ions monitored } \\
(\mathrm{m} / \mathrm{z})\end{array}$ & $\begin{array}{l}\text { No. of MS Scan } \\
\text { Functions }\end{array}$ \\
\hline \multicolumn{7}{|l|}{ PBDEs } \\
\hline 3 & BDE17 & 407 & $406,[\mathrm{M}+2]^{+}$ & 246,248 & $406,408, \underline{246}, 248$ & 2 \\
\hline 3 & BDE28 & 407 & $406,[\mathrm{M}+2]^{+}$ & 246,248 & $406,408, \underline{246}, 248$ & 4 \\
\hline 4 & BDE71 & 486 & $486,[\mathrm{M}-2]^{+}$ & 326,328 & $484,486, \underline{326}, 328$ & 5 \\
\hline 4 & BDE47 & 486 & $486,[\mathrm{M}-2]^{+}$ & 326,328 & $484,486, \underline{326}, 328$ & 6 \\
\hline 4 & BDE66 & 486 & $486,[\mathrm{M}-2]^{+}$ & 326,328 & $484,486, \underline{326}, 328$ & 8 \\
\hline 5 & BDE100 & 565 & $564,[\mathrm{M}+2]^{+}$ & 404,406 & $564,566, \underline{404}, 406$ & 13 \\
\hline 5 & BDE99 & 565 & $564,[\mathrm{M}+2]^{+}$ & 404,406 & $564,566, \underline{404}, 406$ & 17 \\
\hline 5 & BDE85 & 565 & $564,[\mathrm{M}+2]^{+}$ & 404,406 & $564,566, \underline{404}, 406$ & 20 \\
\hline 6 & BDE154 & 644 & $644,[\mathrm{M}-2]^{+}$ & 484,486 & $642,644, \underline{484}, 486$ & 22 \\
\hline 6 & BDE153 & 644 & $644,[\mathrm{M}-2]^{+}$ & 484,486 & $642,644, \underline{484}, 486$ & 26 \\
\hline 6 & BDE138 & 644 & $644,[\mathrm{M}-2]^{+}$ & 484,486 & $642,644, \underline{484}, 486$ & 28 \\
\hline 7 & BDE183 & 723 & $722,[\mathrm{M}+2]^{+}$ & 562,564 & $722,724,562,564$ & 30 \\
\hline 7 & BDE190 & 723 & $722,[\mathrm{M}+2]^{+}$ & 562,564 & $722,724,562,564$ & 31 \\
\hline \multicolumn{7}{|c|}{ MeO-PBDEs } \\
\hline 4 & 2'-MeO-BDE68 & 516 & $516,[\mathrm{M}-2]^{+}$ & $420,422,{ }^{*}\left[\mathrm{M}-\mathrm{CH}_{3} \mathrm{Br}\right]^{+}$ & $514,516, \underline{420}, 422$ & 9 \\
\hline 4 & 6-MeO-BDE47 & 516 & $516,[\mathrm{M}-2]^{+}$ & $356,420,422,{ }^{*}\left[\mathrm{M}-\mathrm{CH}_{3} \mathrm{Br}\right]^{+}$ & $514, \underline{516}, 420,422,356$ & 11 \\
\hline 4 & 5-MeO-BDE47 & 516 & $516,[\mathrm{M}-2]^{+}$ & 356,358 & $514,516, \underline{356}, 358$ & 14 \\
\hline 4 & 4'-MeO-BDE49 & 516 & $516,[\mathrm{M}-2]^{+}$ & 356,358 & $514, \underline{516}, 356,358$ & 15 \\
\hline 5 & 5'-MeO-BDE100 & 595 & $596,[\mathrm{M}-2]^{+}$ & 434,436 & $594,596, \underline{434}, 436$ & 18 \\
\hline 5 & 4'-MeO-BDE103 & 595 & $596,[\mathrm{M}-2]^{+}$ & 434,436 & $\underline{594}, 596,434,436$ & 19 \\
\hline 5 & 5'-MeO-BDE99 & 595 & $596,[\mathrm{M}-2]^{+}$ & 434,436 & $594,596,434, \underline{436}$ & 23 \\
\hline 5 & 4'-MeO-BDE101 & 595 & $596,[\mathrm{M}-2]^{+}$ & 434,436 & $\underline{594}, 596,434,436$ & 24 \\
\hline \multicolumn{7}{|c|}{ MBDE-MXFS } \\
\hline 3 & ${ }^{13} \mathrm{C}_{12}$-BDE-28 & 419 & $418,[\mathrm{M}+2]^{+}$ & 258,260 & $418,420, \underline{258}, 260$ & 3 \\
\hline 4 & ${ }^{13} \mathrm{C}_{12}-\mathrm{BDE}-47$ & 500 & $498,[\mathrm{M}+2]^{+}$ & 338,340 & $498,500, \underline{338,340}$ & 7 \\
\hline 5 & ${ }^{13} \mathrm{C}_{12}-\mathrm{BDE}-100$ & 577 & $576,[\mathrm{M}+2]^{+}$ & 416,418 & $576,578, \underline{416}, 418$ & 12 \\
\hline 5 & ${ }^{13} \mathrm{C}_{12}$-BDE-99 & 577 & $576,[\mathrm{M}+2]^{+}$ & 416,418 & $576,578, \underline{416}, 418$ & 16 \\
\hline 6 & ${ }^{13} \mathrm{C}_{12}$-BDE-154 & 656 & $656,[\mathrm{M}-2]^{+}$ & 494,496 & $654,656, \underline{496}, 498$ & 21 \\
\hline 6 & ${ }^{13} \mathrm{C}_{12}$-BDE-153 & 656 & $656,[\mathrm{M}+2]^{+}$ & 494,496 & $656,658,494, \underline{496}$ & 25 \\
\hline 7 & ${ }^{13} \mathrm{C}_{12}-\mathrm{BDE}-183$ & 735 & $734,[\mathrm{M}+2]^{+}$ & 574,576 & $734,736, \underline{574}, 576$ & 29 \\
\hline \multicolumn{7}{|c|}{ MBDE-MXFR } \\
\hline 4 & ${ }^{13} \mathrm{C}_{12}$-BDE-77 & 500 & $498,[\mathrm{M}+2]^{+}$ & 338,340 & $\underline{498}, 500,336,338$ & 10 \\
\hline 6 & ${ }^{13} \mathrm{C}_{12}-\mathrm{BDE}-138$ & 656 & $656,[\mathrm{M}+2]^{+}$ & 494,496 & $656,658,496,498$ & 27 \\
\hline
\end{tabular}

The ion of underline was indicated for quantitative analysis.

\subsection{Channel Catfish, Crayfish, Fish Feeds and Fishmeal Samples}

Eighty commercial channel catfish and crayfish, and sixty fish feeds and forty fishmeal samples collected from local markets in the Hubei province of China, were used in the present study from August to November, 2013. Muscle tissues of channel catfish and crayfish were collected and homogenized. Fish feeds and fishmeal were filtered through a US 20 mesh screen to ensure the samples uniformity.

\subsection{Determination of MeO-PBDEs and PBDEs}

Analysis of MeO-PBDEs and PBDEs in channel catfish, crayfish, fish feeds and fishmeal samples was prepared by using a literature method and an ISO method modified [15, 35]. The ASE 200 (DIONEX, USA) was used for the pressurized liquid extraction (PLE) experiments. $10 \mathrm{~g}$ of muscle tissue of channel catfish and crayfish, and $2.5 \mathrm{~g}$ of fish feeds and fishmeal were homogenized with Florisil at a proportion of $1 / 2(\mathrm{w} / \mathrm{w})$ after adding $1 \mathrm{~mL}$ of surrogate internal standard solution (the concentrations of
${ }^{13} \mathrm{C}_{12}$-labelled PBDEs 28, 47, 99, 100, 154, 153 and 183 were $100 \mathrm{ng} \mathrm{mL}$ ) were placed in an extraction cell. DCM-acetone $(1: 1, \mathrm{v} / \mathrm{v})$ was used as extraction solvent. The system pressure was set at $1500 \mathrm{psi}$ and the temperature at $100^{\circ} \mathrm{C}(100 \%$ flush volume $)$ with a heat-up time of $6 \mathrm{~min}$. Three cycles of extraction were performed during $5 \mathrm{~min}$ in static mode and the purge time was set at $90 \mathrm{~s}$.

The above total extracts of four kinds of samples were firstly concentrated approximately $1 \mathrm{~mL}$ using iso-octane as the keeper at $40^{\circ} \mathrm{C}$ in a water bath by a K-D vacuum rotary concentrator, and $5.0 \mathrm{~mL}$ of iso-octane was added to dissolve the residue. Then the residue was transferred to a glass tube, and concentrated about $2 \mathrm{~mL}$ by a gentle stream of nitrogen. The resulting mixture was filtrated with a 0.22 $\mu \mathrm{m}$ membrane for next cleanup. Cleanup procedure was performed according to the ISO method modified [35]. The extract was subjected to multi-layer silica column chromatography for the removals of acid compounds, basic compounds, sulfur and sulfur-containing molecules and small amounts of water. The silica column $(22 \mathrm{~mm}$ i.d. $\times 20$ $\mathrm{cm}$ ) was packed in the following sequence: $2 \mathrm{~g}$ of silica, $5 \mathrm{~g}$ 
of $34 \% \mathrm{NaOH}$ silica, $2 \mathrm{~g}$ of silica, $10 \mathrm{~g} 44 \% \mathrm{H}_{2} \mathrm{SO}_{4}$ silica, 2 $\mathrm{g}$ of silica, $5 \mathrm{~g}$ of $10 \% \mathrm{AgNO}_{3}$ silica and $10 \mathrm{~g}$ of $\mathrm{Na}_{2} \mathrm{SO}_{4}$. The column was firstly conditioned with $50 \mathrm{~mL}$ of DCM, and then $50 \mathrm{~mL}$ of cyclohexane. The above extract was transferred to the column. For elution, $50 \mathrm{~mL}$ of cyclohexane was used, and followed by $50 \mathrm{~mL}$ of cyclohexane: DCM (1:1). The flow rate was $2.5 \mathrm{~mL} \mathrm{~min}^{-1}$. The $100 \mathrm{~mL}$ eluates were combined and concentrated approximately $1 \mathrm{~mL}$ using iso-octane as the keeper at $40^{\circ} \mathrm{C}$ in a water bath by a K-D vacuum rotary concentrator, and $5.0 \mathrm{~mL}$ of iso-octane was added to dissolve the residue. Then the residue was transferred to a glass tube, and concentrated almost to dryness by a gentle stream of nitrogen. $0.95 \mathrm{~mL}$ of iso-octane followed by $0.05 \mathrm{~mL}$ syringe standard solution (the concentrations of ${ }^{13} \mathrm{C}_{12}$-BDE77 and 138 were $2 \mu \mathrm{g} \mathrm{mL}{ }^{-1}$ ) were added to dissolve the residue and transferred to an injection vial prior to GC-MS analysis. Sample blanks were taken through all aspects of the experimental procedure.

\subsection{GC-MS}

A PE Clarus 600 GC-MS with electron impact ionization (EI) was used to the simultaneous determinations of MeO-PBDEs and PBDEs. An Elite-5MS column (30 $\mathrm{m} \times 0.25 \mathrm{~mm}$ (id), $0.25 \mu \mathrm{m}$ film thickness; perkinelmer, USA), was used to separate eight MeO-PBDEs, thirteen PBDEs, seven labeled PBDEs (surrogate internal standard) and other two labeled PBDEs (syringe standard). The oven temperature was programmed from $100^{\circ} \mathrm{C}$ (held for $1 \mathrm{~min}$ ) to $200^{\circ} \mathrm{C}$ at $20^{\circ} \mathrm{C} \mathrm{min}{ }^{-1}$ and then to $280^{\circ} \mathrm{C}$ at $2.5^{\circ} \mathrm{C} \mathrm{min}^{-1}$ and finally to $320^{\circ} \mathrm{C}$ at $5^{\circ} \mathrm{C} \mathrm{min}^{-1}$ (held for $10 \mathrm{~min}$ ). The total runtime was $56 \mathrm{~min}$. Helium was used as carrier gas at a constant flow rate of $1 \mathrm{~mL} \mathrm{~min} \mathrm{mi}^{-1} .2 .5$ microliter of samples and standards were injected in splitless injection mode at an injector temperature of $275^{\circ} \mathrm{C}$. The information of retention times (RT), start time and end time of retention window, No. of MS scan functions and quantitation reference for MeO-PBDEs, PBDEs, MBDE-MXFS and MBDE-MXFR on Elite-5MS were presented in table 2.

Table 2. Retention times (RT), start time and end time of retention window, No. of MS scan functions, quantitation reference for MeO-PBDEs, PBDEs, MBDE-MXFS and MBDE-MXFR on Elite-5MS, and LOQ of MeO-PBDEs and PBDEs in channel catfish, crayfish, fish feeds and fishmeal

\begin{tabular}{|c|c|c|c|c|c|c|c|}
\hline \multirow[b]{2}{*}{ Br No. } & \multirow[b]{2}{*}{ Compounds } & \multirow{2}{*}{$\begin{array}{l}\text { Quantitation } \\
\text { reference }\end{array}$} & \multirow[b]{2}{*}{$\begin{array}{l}\text { Retention } \\
\text { times (RT) }\end{array}$} & \multirow{2}{*}{$\begin{array}{l}\text { Start time and end } \\
\text { time of Retention } \\
\text { Window }\end{array}$} & \multirow{2}{*}{$\begin{array}{l}\text { No. of MS } \\
\text { Scan } \\
\text { Functions } \\
\end{array}$} & \multicolumn{2}{|l|}{ LOQ } \\
\hline & & & & & & $\begin{array}{l}\text { Channel catfish and } \\
\text { crayfish }\left(\mu \mathrm{g} \mathrm{kg}^{-1}\right)\end{array}$ & $\begin{array}{l}\text { Fish feeds and } \\
\text { fishmeal }\left(\mu \mathrm{g} \mathrm{kg}^{-1}\right)\end{array}$ \\
\hline \multicolumn{8}{|c|}{ Compounds using ${ }^{13} \mathrm{C}_{12}$-BDE-77 as labeled injection internal standard } \\
\hline 3 & BDE17 & ${ }^{13} \mathrm{C}_{12}$-BDE-28 & 13.84 & $13.44 \sim 14.38$ & 2 & 0.25 & 1 \\
\hline 3 & BDE28 & ${ }^{13} \mathrm{C}_{12}$-BDE-28 & 14.66 & $14.24 \sim 15.25$ & 4 & 0.25 & 1 \\
\hline 4 & BDE71 & ${ }^{13} \mathrm{C}_{12}-\mathrm{BDE}-47$ & 19.31 & $18.93 \sim 19.90$ & 5 & 0.5 & 2 \\
\hline 4 & BDE47 & ${ }^{13} \mathrm{C}_{12}$-BDE-47 & 20.02 & $19.66 \sim 20.72$ & 6 & 0.5 & 2 \\
\hline 4 & BDE66 & ${ }^{13} \mathrm{C}_{12}-\mathrm{BDE}-47$ & 21.03 & $20.64 \sim 21.73$ & 8 & 0.5 & 2 \\
\hline 5 & BDE100 & ${ }^{13} \mathrm{C}_{12}$-BDE-100 & 24.65 & $24.27 \sim 25.30$ & 13 & 1 & 4 \\
\hline 5 & BDE99 & ${ }^{13} \mathrm{C}_{12}$-BDE-99 & 26.28 & $25.96 \sim 26.90$ & 17 & 1 & 4 \\
\hline 5 & BDE85 & ${ }^{13} \mathrm{C}_{12}$-BDE-99 & 28.95 & $28.61 \sim 29.73$ & 20 & 1 & 4 \\
\hline \multicolumn{8}{|c|}{ Compounds using ${ }^{13} \mathrm{C}_{12}$-BDE-138 as labeled injection internal standard } \\
\hline 6 & BDE154 & ${ }^{13} \mathrm{C}_{12}-\mathrm{BDE}-154$ & 30.27 & $29.86 \sim 30.91$ & 22 & 1 & 4 \\
\hline 6 & BDE153 & ${ }^{13} \mathrm{C}_{12}-\mathrm{BDE}-153$ & 32.57 & $32.23 \sim 33.22$ & 26 & 1 & 4 \\
\hline 6 & BDE138 & ${ }^{13} \mathrm{C}_{12}-\mathrm{BDE}-153$ & 35.40 & $35.02 \sim 36.05$ & 28 & 2.5 & 10 \\
\hline 7 & BDE183 & ${ }^{13} \mathrm{C}_{12}-\mathrm{BDE}-183$ & 38.56 & $38.22 \sim 39.18$ & 30 & 2.5 & 10 \\
\hline 7 & BDE190 & ${ }^{13} \mathrm{C}_{12}-\mathrm{BDE}-183$ & 41.84 & $41.46 \sim 42.42$ & 31 & 5 & 20 \\
\hline \multicolumn{8}{|c|}{ Compounds using ${ }^{13} \mathrm{C}_{12}$-BDE-77 as labeled injection internal standard } \\
\hline 4 & 2'-MeO-BDE68 & ${ }^{13} \mathrm{C}_{12}-\mathrm{BDE}-100$ & 22.44 & $22.00 \sim 23.06$ & 9 & 1 & 4 \\
\hline 4 & 6-MeO-BDE47 & ${ }^{13} \mathrm{C}_{12}-\mathrm{BDE}-100$ & 23.25 & $22.81 \sim 23.87$ & 11 & 1 & 4 \\
\hline 4 & 5-MeO-BDE47 & ${ }^{13} \mathrm{C}_{12}-\mathrm{BDE}-100$ & 24.84 & $24.28 \sim 25.57$ & 14 & 1 & 4 \\
\hline 4 & 4'-MeO-BDE49 & ${ }^{13} \mathrm{C}_{12}-\mathrm{BDE}-100$ & 25.15 & $24.66 \sim 25.95$ & 15 & 2.5 & 10 \\
\hline \multicolumn{8}{|c|}{ Compounds using ${ }^{13} \mathrm{C}_{12}$-BDE-138 as labeled injection internal standard } \\
\hline 5 & 5'-MeO-BDE100 & ${ }^{13} \mathrm{C}_{12}-\mathrm{BDE}-154$ & 28.32 & $27.88 \sim 29.00$ & 18 & 2.5 & 10 \\
\hline 5 & 4'-MeO-BDE103 & ${ }^{13} \mathrm{C}_{12}-\mathrm{BDE}-154$ & 28.75 & $28.21 \sim 29.55$ & 19 & 2.5 & 10 \\
\hline 5 & 5'-MeO-BDE99 & ${ }^{13} \mathrm{C}_{12}$-BDE- 154 & 30.89 & $30.48 \sim 31.56$ & 23 & 2.5 & 10 \\
\hline 5 & 4'-MeO-BDE101 & ${ }^{13} \mathrm{C}_{12}$-BDE-154 & 31.25 & $30.75 \sim 32.09$ & 24 & 5 & 20 \\
\hline \multicolumn{8}{|c|}{ Labeled compounds } \\
\hline 3 & ${ }^{13} \mathrm{C}_{12}$-BDE-28 & ${ }^{13} \mathrm{C}_{12}$-BDE-77 & 14.64 & $14.21 \sim 15.28$ & 3 & - & - \\
\hline 4 & ${ }^{13} \mathrm{C}_{12}-\mathrm{BDE}-47$ & ${ }^{13} \mathrm{C}_{12}$-BDE-77 & 20.03 & $19.68 \sim 20.72$ & 7 & - & - \\
\hline 5 & ${ }^{13} \mathrm{C}_{12}$-BDE-100 & ${ }^{13} \mathrm{C}_{12}$-BDE-77 & 24.64 & $24.21 \sim 25.27$ & 12 & - & - \\
\hline 5 & ${ }^{13} \mathrm{C}_{12}-\mathrm{BDE}-99$ & ${ }^{13} \mathrm{C}_{12}$-BDE-77 & 26.26 & $25.93 \sim 26.99$ & 16 & - & - \\
\hline 6 & ${ }^{13} \mathrm{C}_{12}-\mathrm{BDE}-154$ & ${ }^{13} \mathrm{C}_{12}-\mathrm{BDE}-138$ & 30.25 & $29.82 \sim 30.90$ & 21 & - & - \\
\hline 6 & ${ }^{13} \mathrm{C}_{12}$-BDE-153 & ${ }^{13} \mathrm{C}_{12}-\mathrm{BDE}-138$ & 32.55 & $32.20 \sim 33.20$ & 25 & - & - \\
\hline 7 & ${ }^{13} \mathrm{C}_{12}-\mathrm{BDE}-183$ & ${ }^{13} \mathrm{C}_{12}-\mathrm{BDE}-138$ & 38.52 & $38.18 \sim 39.20$ & 29 & - & - \\
\hline \multicolumn{8}{|c|}{ Labeled injection internal standards } \\
\hline 4 & ${ }^{13} \mathrm{C}_{12}-\mathrm{BDE}-77$ & ${ }^{13} \mathrm{C}_{12}-\mathrm{BDE}-77$ & 22.54 & $22.17 \sim 23.22$ & 10 & - & - \\
\hline 6 & ${ }^{13} \mathrm{C}_{12}-\mathrm{BDE}-138$ & ${ }^{13} \mathrm{C}_{12}-\mathrm{BDE}-138$ & 35.38 & $35.00 \sim 36.10$ & 27 & - & - \\
\hline
\end{tabular}

The transverse line was indicated no data. 
MS operating conditions were the following: electron ionization mode using automatic gain control (AGC) with electron energy of $70 \mathrm{eV}$ and an emission current of 250 $\mu \mathrm{A}$. The transfer line and ion source temperatures were kept at $320^{\circ} \mathrm{C}$ and $250^{\circ} \mathrm{C}$, respectively. The electron multiplier voltage was set to $370 \mathrm{~V}$.

Quantitative determination by GC-MS (EI+) was in the selected ion monitoring (SIM) mode. The ions monitored for PBDEs and MeO-PBDEs, including labeled PBDEs were presented in table 1 .

\subsection{Quantification and Quality Control}

Our laboratory has established a quality assurance system as per ISO/IEC 17025: 2005 for strict controls over personnel, conditions of instruments, experimental situation, etc. Eight MeO-PBDEs and thirteen PBDEs were quantified by isotope dilution or internal standard using MBDE-MXFS, and the quantification of real samples was dealt with by isotope dilution or internal standard in this study. Isotope dilution quantitation, internal standard quantitation and labeled compound recovery were used according to an EPA method [36]. On the one hand, isotope dilution was used for calibration for MeO-PBDEs and PBDEs that have a labeled analog, for example, for BDE28, on the other hand, internal standard was applied to determination of $\mathrm{MeO}-\mathrm{PBDEs}$ and PBDEs for which a labeled analog was not used in the study. The detailed information of quantitation reference for eight MeO-PBDEs and thirteen PBDEs, was given in table 2.

In order to ensure the accuracy of the results and the applicability of the method in the study, in the case of repeated analyses of the spiking and real samples, the guideline ranges for the deviation of the experimentally determined recovery corrected mean mass fraction from the spiking value must meet the requirements of the European Union document 2002/657/EC: Commission Decision of 12 August 2002 implementing Council Directive 96/23/EC concerning the performance of analytical methods and the interpretation of results. In addition, the recovery efficiency of all MBDE-MXFS by MBDE-MXFR shall be $60 \%$ or better.

\section{Results and Discussion}

\subsection{Method Development}

The analysis method in the study was principally described by two literature methods as indicated above, but some important steps and crucial parameters were modified and intensified compared with literatures in this study. The main aspects regarding sample extraction and sample cleanup were intensified during the development of the method.

Firstly, for sample extraction, PBDEs and MeO-PBDEs only fish samples were analyzed, and five to $10 \mathrm{~g}$ of the sample (wet weight) were homogenized with hydromatrix and extracted by PLE [15]. In contrast to the described method [15], the extraction in detail in the present study was reported to ensure the experimental feasibility. Moreover, new sample species such as crayfish, fish feeds and fishmeal were applied in this study, and for the first time analysis method of PBDEs and MeO-PBDEs in crayfish, fish feeds and fishmeal by isotopic dilution GC-MS was established in this paper. Because crayfish contained comparative lipids as channel catfish, $10 \mathrm{~g}$ of the same mass for crayfish was chosen. Three factors, lipid contents of fish feeds and fishmeal, feasibility of filtration with a $0.22 \mu \mathrm{m}$ membrane and $2.0 \mathrm{~mL}$ of sample injection volume subjected to multi-layer silica column chromatography during the sample preparation and cleanup, were carefully taken into consideration, and $2.5 \mathrm{~g}$ of fish feeds and fishmeal were chosen.

Next, multi-layer silica cleanup for the removals of acid compounds, basic compounds, sulfur and sulfur-containing molecules and small amounts of water was a very important step for determination of PBDEs in biotic samples [35]. It was also considered that elution solvents and their compositions were most important factor for MeO-PBDEs in the study. Elution solvents and their compositions were modified in contrast to the ISO method [35]. For elution, $50 \mathrm{~mL}$ of cyclohexane was firstly used to ensure that all impurities could be well adsorbed in the silica, and cyclohexane eluent need be collected because a small amount of MeO-PBDEs and PBDEs were also eluted down. Then MeO-PBDEs and PBDEs were completely eluted by $50 \mathrm{~mL}$ of mixed solvent of cyclohexane and DCM. The volume ratio of cyclohexane and DCM were optimized according to the below method of description, involving four groups of experiments.

$1 \mathrm{~mL}$ of the mixed working standard (the concentration of BDE17, BDE28, BDE47, BDE66, BDE71, BDE85, BDE99, BDE100, BDE138, BDE153, BDE154, BDE183 and BDE190 were $100 \mathrm{ng} \mathrm{mL}^{-1}$, the concentration of 5-MeO-BDE47, 6-MeO-BDE47, 4'-MeO-BDE49, 2'-MeO-BDE68, 5'-MeO-BDE99, 5'-MeO-BDE100, $4^{\prime}-\mathrm{MeO}-\mathrm{BDE} 101$ and $4^{\prime}-\mathrm{MeO}-\mathrm{BDE} 103$ were $100 \mathrm{ng} \mathrm{mL}^{-1}$, the concentrations of ${ }^{13} \mathrm{C}_{12}$-labelled PBDEs 28, 47, 99, 100, 154,153 and 183 were $100 \mathrm{ng} \mathrm{mL}^{-1}$, and the concentration of ${ }^{13} \mathrm{C}_{12}$-labelled PBDEs 77 and 138 were $100 \mathrm{ng} \mathrm{mL}^{-1}$ ) was subjected to four multi-layer silica columns, respectively. Four $50 \mathrm{~mL}$ of cyclohexane was firstly used to elute in four multi-layer silica columns, then $50 \mathrm{~mL}$ of cyclohexane: DCM (8:2), $50 \mathrm{~mL}$ of cyclohexane: DCM (7:3), $50 \mathrm{~mL}$ of cyclohexane: DCM (6:4) and $50 \mathrm{~mL}$ of cyclohexane: DCM (5:5), were respectively used to elute in four multi-layer silica columns. The flow rate is $2.5 \mathrm{~mL} \mathrm{~min}^{-1}$. The next experiments were conducted according to the section 2 . The results showed the recoveries of all these compounds were most excellent by elution of $50 \mathrm{~mL}$ of cyclohexane: DCM (5:5). Similarly, the blank samples of channel catfish, crayfish, fish feeds and fishmeal spiked at the same level as above mixed working standard were prepared prior to 
sample extractions, and the sample extractions were carried out according to the section 2. The sample cleanup of multi-layer silica column and following experiments were conducted according to the above method for the mixed working standard. It was also interesting that the recoveries of all these compounds were also most excellent by elution of $50 \mathrm{~mL}$ of cyclohexane: DCM (5:5). Moreover, the fractions collected were clean and contained little impurity, which indicated the impurity removal was successful. Therefore, the cleanup procedure that $50 \mathrm{~mL}$ of cyclohexane was used, and followed by $50 \mathrm{~mL}$ of cyclohexane: DCM (1:1) was chosen.

Finally, GC and MS conditions were also very important factors for determinations of MeO-PBDEs and PBDEs, including ${ }^{13} \mathrm{C}_{12}$-labelled PBDEs. For MS acquisition, qualitative and quantitative analysis were performed using SIM. Table 1 provided further information optimized for these parameters, especially about quantitation reference for eight MeO-PBDEs and thirteen PBDEs, ensuring the operability of quantitation analysis. GC conditions were also optimized, including temperature programmed conditions and separation column. Temperature programmed conditions were optimized to ensure excellent separation efficiency of MeO-PBDEs, PBDEs and ${ }^{13} \mathrm{C}_{12}$-labelled PBDEs. Different separation columns were selected and compared to gain a more suitable separation effect, ensuring excellent experiment results.

\subsection{Calibration Curves, Limits of Quantitation and Recovery Rates}

Seven mixed series working standards of MeO-PBDEs and PBDEs, including MBDE-MXFS and MBDE-MXFR were prepared according to table 3. Linear calibration curves for MeO-PBDEs and PBDEs by isotopic dilution and internal standard method were obtained with a $\gamma 2$ correlation coefficient of more than 0.9991 . The linearity was checked by calculating the standard deviation of the average of response factors (peak area ratios divided by the corresponding analyte concentration ratios of all standards), which was $<15 \%$ assuming a linear response.

Table 3. Seven mixed series working standards of MeO-PBDEs, PBDEs, MBDE-MXFS and MBDE-MXFR

\begin{tabular}{|c|c|c|c|c|c|c|c|c|}
\hline \multirow{3}{*}{ Br No. } & \multirow{3}{*}{ Compound } & \multicolumn{7}{|c|}{ Solutions (Calibration standard solutions were prepared by dilution of standard stock solutions in iso-octane) } \\
\hline & & 1 & 2 & 3 & 4 & 5 & 6 & 7 \\
\hline & & \multicolumn{7}{|c|}{ ng $\mathbf{~ m L}^{-1}$} \\
\hline \multicolumn{2}{|l|}{ PBDEs } & \multicolumn{7}{|c|}{$\begin{array}{l}\text { PBDEs standard stock solutions, Mixture of Commonly PBDE Congeners, } 5 \mu \mathrm{g} \mathrm{mL} \mathrm{m}^{-1} \text { in iso-octane and toluene } \\
(97.5: 2.5)\end{array}$} \\
\hline 3 & BDE17 & 5 & 10 & 25 & 50 & 100 & 150 & 250 \\
\hline 3 & BDE28 & 5 & 10 & 25 & 50 & 100 & 150 & 250 \\
\hline 4 & BDE71 & 5 & 10 & 25 & 50 & 100 & 150 & 250 \\
\hline 4 & BDE47 & 5 & 10 & 25 & 50 & 100 & 150 & 250 \\
\hline 4 & BDE66 & 5 & 10 & 25 & 50 & 100 & 150 & 250 \\
\hline 5 & BDE100 & 5 & 10 & 25 & 50 & 100 & 150 & 250 \\
\hline 5 & BDE99 & 5 & 10 & 25 & 50 & 100 & 150 & 250 \\
\hline 5 & BDE85 & 5 & 10 & 25 & 50 & 100 & 150 & 250 \\
\hline 6 & BDE154 & 5 & 10 & 25 & 50 & 100 & 150 & 250 \\
\hline 6 & BDE153 & 5 & 10 & 25 & 50 & 100 & 150 & 250 \\
\hline 6 & BDE138 & 5 & 10 & 25 & 50 & 100 & 150 & 250 \\
\hline 7 & BDE183 & 5 & 10 & 25 & 50 & 100 & 150 & 250 \\
\hline 7 & BDE190 & 5 & 10 & 25 & 50 & 100 & 150 & 250 \\
\hline \multicolumn{2}{|c|}{ MeO-PBDEs } & \multicolumn{7}{|c|}{ MeO-PBDEs standard stock solutions, $5 \mu \mathrm{g} \mathrm{mL}^{-1}$ in nonane and toluene $(92: 8)$} \\
\hline 4 & 2'-MeO-BDE68 & 5 & 10 & 25 & 50 & 100 & 150 & 250 \\
\hline 4 & 6-MeO-BDE47 & 5 & 10 & 25 & 50 & 100 & 150 & 250 \\
\hline 4 & 5-MeO-BDE47 & 5 & 10 & 25 & 50 & 100 & 150 & 250 \\
\hline 4 & 4'-MeO-BDE49 & 5 & 10 & 25 & 50 & 100 & 150 & 250 \\
\hline 5 & 5'-MeO-BDE100 & 5 & 10 & 25 & 50 & 100 & 150 & 250 \\
\hline 5 & 4'-MeO-BDE103 & 5 & 10 & 25 & 50 & 100 & 150 & 250 \\
\hline 5 & 5'-MeO-BDE99 & 5 & 10 & 25 & 50 & 100 & 150 & 250 \\
\hline 5 & 4'-MeO-BDE101 & 5 & 10 & 25 & 50 & 100 & 150 & 250 \\
\hline \multicolumn{2}{|c|}{ MBDE-MXFS } & \multicolumn{7}{|c|}{ Surrogate internal standard for $\mathrm{EI}+, 2 \mu \mathrm{g} \mathrm{mL}^{-1}$ of each congener in toluene and nonane $(74.8: 25.2)$} \\
\hline 3 & ${ }^{13} \mathrm{C}_{12}-\mathrm{BDE}-28$ & 100 & 100 & 100 & 100 & 100 & 100 & 100 \\
\hline 4 & ${ }^{13} \mathrm{C}_{12}-\mathrm{BDE}-47$ & 100 & 100 & 100 & 100 & 100 & 100 & 100 \\
\hline 5 & ${ }^{13} \mathrm{C}_{12}$-BDE-100 & 100 & 100 & 100 & 100 & 100 & 100 & 100 \\
\hline 5 & ${ }^{13} \mathrm{C}_{12}$-BDE-99 & 100 & 100 & 100 & 100 & 100 & 100 & 100 \\
\hline 6 & ${ }^{13} \mathrm{C}_{12}-\mathrm{BDE}-154$ & 100 & 100 & 100 & 100 & 100 & 100 & 100 \\
\hline 6 & ${ }^{13} \mathrm{C}_{12}$-BDE-153 & 100 & 100 & 100 & 100 & 100 & 100 & 100 \\
\hline 7 & ${ }^{13} \mathrm{C}_{12}-\mathrm{BDE}-183$ & 100 & 100 & 100 & 100 & 100 & 100 & 100 \\
\hline \multicolumn{2}{|c|}{ MBDE-MXFR } & \multicolumn{7}{|c|}{ Syringe standards, $2 \mu \mathrm{g} \mathrm{mL}^{-1}$ in toluene and nonane (92.8:7.2) } \\
\hline 4 & ${ }^{13} \mathrm{C}_{12}-\mathrm{BDE}-77$ & 100 & 100 & 100 & 100 & 100 & 100 & 100 \\
\hline 6 & ${ }^{13} \mathrm{C}_{12}$-BDE-138 & 100 & 100 & 100 & 100 & 100 & 100 & 100 \\
\hline
\end{tabular}


The limit of quantitation (LOQ), defined as the concentration of analyte which yielded a peak-to-peak signal-to-noise ratio of at least 10:1, was calculated by running a series of 10 negative extracts. The detailed information for LOQ of channel catfish, crayfish, fish feeds and fishmeal was presented in table 2.

Spike recoveries of MeO-PBDEs and PBDEs in these productions were studied. Table 4 provided further information. Average recoveries and standard deviation (SD) of all concentrations analyzed triple samples met the requirements of the European Union document 2002/657/EC: Commission Decision of 12 August 2002 implementing Council Directive 96/23/EC concerning the performance of analytical methods and the interpretation of results. In addition, the recovery efficiency of all MBDE-MXFS by MBDE-MXFR was more than $80 \%$.

Table 4. Average recoveries and standard deviation of MeO-PBDEs and PBDEs in channel catfish, crayfish, fish feeds and fishmeal (\%R \pm SD, $n=3$ ) ( $\mu g \mathrm{~kg}{ }^{-1}$ wet weight)

\begin{tabular}{|c|c|c|c|c|c|c|c|c|c|c|c|c|c|c|}
\hline \multirow{2}{*}{$\begin{array}{l}\text { Br } \\
\text { No. }\end{array}$} & \multirow{2}{*}{ Compound } & \multirow{2}{*}{$\begin{array}{l}\text { Quantitation } \\
\text { reference }\end{array}$} & \multicolumn{3}{|c|}{$\begin{array}{l}\text { Recoveries from spiked } \\
\text { channel catfish }\end{array}$} & \multicolumn{3}{|c|}{$\begin{array}{l}\text { Recoveries from spiked } \\
\text { crayfish }\end{array}$} & \multicolumn{3}{|c|}{$\begin{array}{l}\text { Recoveries from spiked } \\
\text { fish feeds }\end{array}$} & \multicolumn{3}{|c|}{$\begin{array}{l}\text { Recoveries from spiked } \\
\text { fishmeal }\end{array}$} \\
\hline & & & 2.5 & 10 & 25 & 2.5 & 10 & 25 & 10 & 40 & 100 & 10 & 40 & 100 \\
\hline \multicolumn{15}{|c|}{ Compounds using ${ }^{13} \mathrm{C}_{12}$-BDE-77 as labeled injection internal standard } \\
\hline 3 & BDE17 & ${ }^{13} \mathrm{C}_{12}-\mathrm{BDE}-28$ & $92 \pm 7$ & $92 \pm 5$ & $96 \pm 6$ & $84 \pm 10$ & $94 \pm 8$ & $96 \pm 12$ & $92 \pm 5$ & $103 \pm 5$ & $102 \pm 6$ & $96 \pm 13$ & $99 \pm 8$ & $104 \pm 7$ \\
\hline 3 & BDE28 & ${ }^{13} \mathrm{C}_{12}-\mathrm{BDE}-28$ & $87 \pm 7$ & $96 \pm 5$ & $94 \pm 8$ & $89 \pm 13$ & $90 \pm 7$ & $92 \pm 8$ & $96 \pm 5$ & $101 \pm 9$ & $98 \pm 9$ & $90 \pm 6$ & $100 \pm 8$ & $100 \pm 7$ \\
\hline 4 & BDE71 & ${ }^{13} \mathrm{C}_{12}-\mathrm{BDE}-47$ & $74 \pm 6$ & $89 \pm 10$ & $95 \pm 5$ & $76 \pm 11$ & $90 \pm 11$ & $94 \pm 10$ & $84 \pm 6$ & $101 \pm 9$ & $101 \pm 7$ & $88 \pm 11$ & $98 \pm 7$ & $99 \pm 6$ \\
\hline 4 & BDE47 & ${ }^{13} \mathrm{C}_{12}-\mathrm{BDE}-47$ & $87 \pm 5$ & $91 \pm 7$ & $96 \pm 10$ & $82 \pm 4$ & $84 \pm 8$ & $91 \pm 10$ & $93 \pm 7$ & $99 \pm 6$ & $101 \pm 7$ & $90 \pm 7$ & $100 \pm 5$ & $101 \pm 7$ \\
\hline 4 & BDE66 & ${ }^{13} \mathrm{C}_{12}-\mathrm{BDE}-47$ & $78 \pm 9$ & $86 \pm 5$ & $93 \pm 12$ & $75 \pm 5$ & $90 \pm 10$ & $90 \pm 10$ & $92 \pm 10$ & $101 \pm 9$ & $100 \pm 9$ & $90 \pm 10$ & $95 \pm 6$ & $98 \pm 5$ \\
\hline 5 & BDE100 & ${ }^{13} \mathrm{C}_{12}$-BDE-100 & $82 \pm 12$ & $83 \pm 6$ & $95 \pm 5$ & $83 \pm 11$ & $86 \pm 9$ & $96 \pm 5$ & $91 \pm 8$ & $103 \pm 8$ & $103 \pm 8$ & $92 \pm 8$ & $99 \pm 8$ & $100 \pm 6$ \\
\hline 5 & BDE99 & ${ }^{13} \mathrm{C}_{12}-\mathrm{BDE}-99$ & $81 \pm 14$ & $85 \pm 7$ & $94 \pm 9$ & $82 \pm 10$ & $86 \pm 7$ & $93 \pm 10$ & $90 \pm 11$ & $96 \pm 7$ & $97 \pm 5$ & $93 \pm 10$ & $93 \pm 10$ & $102 \pm 5$ \\
\hline 5 & BDE85 & ${ }^{13} \mathrm{C}_{12}$-BDE-99 & $78 \pm 16$ & $85 \pm 6$ & $87 \pm 5$ & $77 \pm 6$ & $86 \pm 7$ & $92 \pm 8$ & $87 \pm 5$ & $95 \pm 7$ & $101 \pm 6$ & $86 \pm 7$ & $86 \pm 7$ & $97 \pm 7$ \\
\hline \multicolumn{15}{|c|}{ Compounds using ${ }^{13} \mathrm{C}_{12}$-BDE-138 as labeled injection internal standard } \\
\hline 6 & BDE154 & ${ }^{13} \mathrm{C}_{12}$-BDE-154 & $74 \pm 7$ & $84 \pm 6$ & $89 \pm 7$ & $78 \pm 5$ & $85 \pm 8$ & $88 \pm 12$ & $87 \pm 8$ & $96 \pm 10$ & $96 \pm 11$ & $86 \pm 4$ & $93 \pm 8$ & $101 \pm 7$ \\
\hline 6 & BDE153 & ${ }^{13} \mathrm{C}_{12}-\mathrm{BDE}-153$ & $75 \pm 8$ & $82 \pm 4$ & $90 \pm 9$ & $73 \pm 8$ & $84 \pm 5$ & $90 \pm 5$ & $88 \pm 9$ & $90 \pm 7$ & $96 \pm 10$ & $85 \pm 10$ & $93 \pm 7$ & $98 \pm 8$ \\
\hline 6 & BDE138 & ${ }^{13} \mathrm{C}_{12}$-BDE- 153 & $75 \pm 8$ & $82 \pm 4$ & $85 \pm 7$ & $73 \pm 6$ & $85 \pm 10$ & $84 \pm 5$ & $85 \pm 7$ & $87 \pm 6$ & $94 \pm 7$ & $85 \pm 12$ & $90 \pm 9$ & $90 \pm 9$ \\
\hline 7 & BDE183 & ${ }^{13} \mathrm{C}_{12}-\mathrm{BDE}-183$ & $83 \pm 8$ & $83 \pm 3$ & $85 \pm 5$ & $78 \pm 9$ & $87 \pm 11$ & $85 \pm 4$ & $85 \pm 4$ & $97 \pm 11$ & $91 \pm 7$ & $84 \pm 8$ & $91 \pm 10$ & $91 \pm 8$ \\
\hline 7 & BDE190 & ${ }^{13} \mathrm{C}_{12}$-BDE- 183 & - & $80 \pm 13$ & $84 \pm 5$ & - & $82 \pm 14$ & $84 \pm 8$ & - & $91 \pm 9$ & $90 \pm 5$ & - & $88 \pm 9$ & $87 \pm 6$ \\
\hline \multicolumn{15}{|c|}{ Compounds using ${ }^{13} \mathrm{C}_{12}$-BDE-77 as labeled injection internal standard } \\
\hline 4 & 2'-MeO-BDE68 & ${ }^{13} \mathrm{C}_{12}-\mathrm{BDE}-100$ & $80 \pm 10$ & $96 \pm 8$ & $102 \pm 9$ & $77 \pm 9$ & $96 \pm 3$ & $96 \pm 13$ & $99 \pm 6$ & $103 \pm 6$ & $101 \pm 5$ & $100 \pm 9$ & $102 \pm 8$ & $102 \pm 6$ \\
\hline 4 & 6-MeO-BDE47 & ${ }^{13} \mathrm{C}_{12}$-BDE- 100 & $77 \pm 7$ & $93 \pm 13$ & $96 \pm 8$ & $75 \pm 8$ & $100 \pm 7$ & $100 \pm 9$ & $100 \pm 5$ & $100 \pm 8$ & $98 \pm 7$ & $103 \pm 7$ & $103 \pm 7$ & $103 \pm 7$ \\
\hline 4 & 5-MeO-BDE47 & ${ }^{13} \mathrm{C}_{12}$-BDE-100 & $78 \pm 11$ & $100 \pm 8$ & $96 \pm 5$ & $75 \pm 5$ & $94 \pm 10$ & $94 \pm 10$ & $99 \pm 9$ & $99 \pm 8$ & $101 \pm 9$ & $92 \pm 11$ & $98 \pm 6$ & $100 \pm 6$ \\
\hline 4 & 4'-MeO-BDE49 & ${ }^{13} \mathrm{C}_{12}$-BDE- 100 & $79 \pm 9$ & $85 \pm 8$ & $92 \pm 6$ & $86 \pm 5$ & $95 \pm 8$ & $95 \pm 7$ & $95 \pm 7$ & $94 \pm 6$ & $100 \pm 4$ & $93 \pm 7$ & $95 \pm 7$ & $100 \pm 6$ \\
\hline \multicolumn{15}{|c|}{ Compounds using ${ }^{13} \mathrm{C}_{12}$-BDE-138 as labeled injection internal standard } \\
\hline 5 & 5'-MeO-BDE100 & ${ }^{13} \mathrm{C}_{12}$-BDE- 154 & $78 \pm 12$ & $86 \pm 6$ & $91 \pm 4$ & $76 \pm 11$ & $86 \pm 6$ & $86 \pm 5$ & $95 \pm 3$ & $97 \pm 5$ & $102 \pm 9$ & $91 \pm 8$ & $99 \pm 7$ & $100 \pm 7$ \\
\hline 5 & $4^{\prime}-\mathrm{MeO}-\mathrm{BDE} 103$ & ${ }^{13} \mathrm{C}_{12}$-BDE-154 & $76 \pm 7$ & $85 \pm 7$ & $85 \pm 4$ & $77 \pm 6$ & $86 \pm 10$ & $89 \pm 10$ & $86 \pm 5$ & $97 \pm 7$ & $100 \pm 6$ & $89 \pm 10$ & $104 \pm 7$ & $98 \pm 12$ \\
\hline 5 & 5'-MeO-BDE99 & ${ }^{13} \mathrm{C}_{12}-\mathrm{BDE}-154$ & $80 \pm 8$ & $85 \pm 7$ & $88 \pm 5$ & $79 \pm 13$ & $85 \pm 10$ & $89 \pm 6$ & $88 \pm 10$ & $101 \pm 7$ & $100 \pm 6$ & $86 \pm 8$ & $94 \pm 6$ & $103 \pm 6$ \\
\hline 5 & 4'-MeO-BDE101 & ${ }^{13} \mathrm{C}_{12}$-BDE-154 & - & $81 \pm 12$ & $87 \pm 5$ & - & $82 \pm 8$ & $87 \pm 5$ & - & $97 \pm 7$ & $95 \pm 6$ & - & $92 \pm 6$ & $94 \pm 6$ \\
\hline
\end{tabular}

The transverse line was indicated no data because the spiked amount was below LOQ.

\subsection{Analysis of Channel Catfish, Crayfish, Fish Feeds and Fishmeal}

GC-MS chromatogram of a mixed standard solution of MeO-PBDEs and PBDEs (the concentration of BDE17, BDE28, BDE47, BDE66, BDE71, BDE85, BDE99, BDE100, BDE138, BDE153, BDE154, BDE183 and

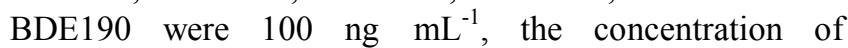

5-MeO-BDE47, 6-MeO-BDE47, 4'-MeO-BDE49, 2'-MeO-BDE68, 5'-MeO-BDE99, 5'-MeO-BDE100, $4^{\prime}$-MeO-BDE101 and 4'-MeO-BDE103 were $100 \mathrm{ng} \mathrm{mL}^{-1}$, the concentrations of ${ }^{13} \mathrm{C}_{12}$-labelled PBDEs 28, 47, 99, 100, 154,153 and 183 as surrogate internal standard were $100 \mathrm{ng}$ $\mathrm{mL}^{-1}$, and the concentration of ${ }^{13} \mathrm{C}_{12}$-labelled PBDEs 77 and 138 as syringe standard were $100 \mathrm{ng} \mathrm{mL}^{-1}$ ), was shown in Fig.1. 


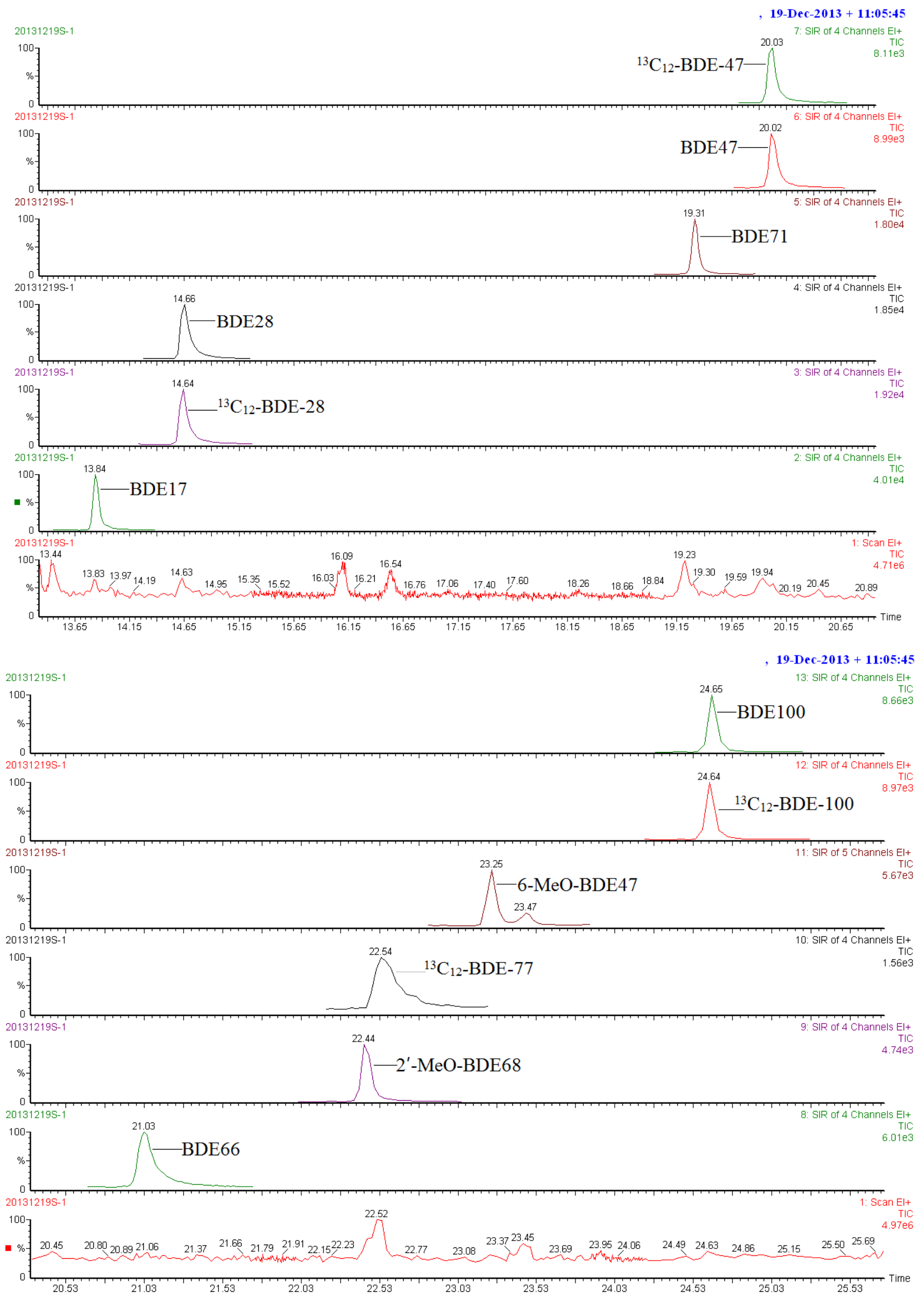




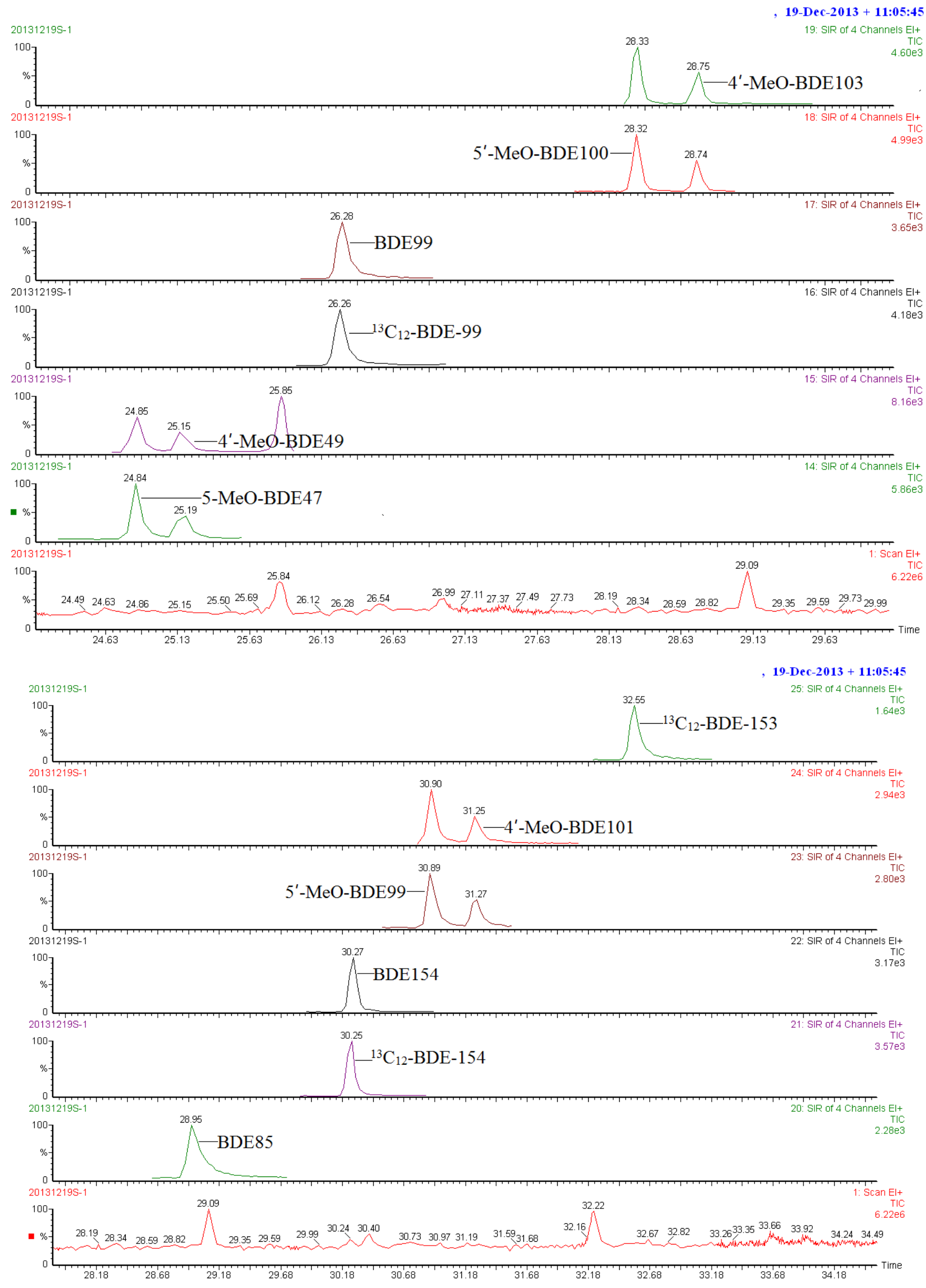




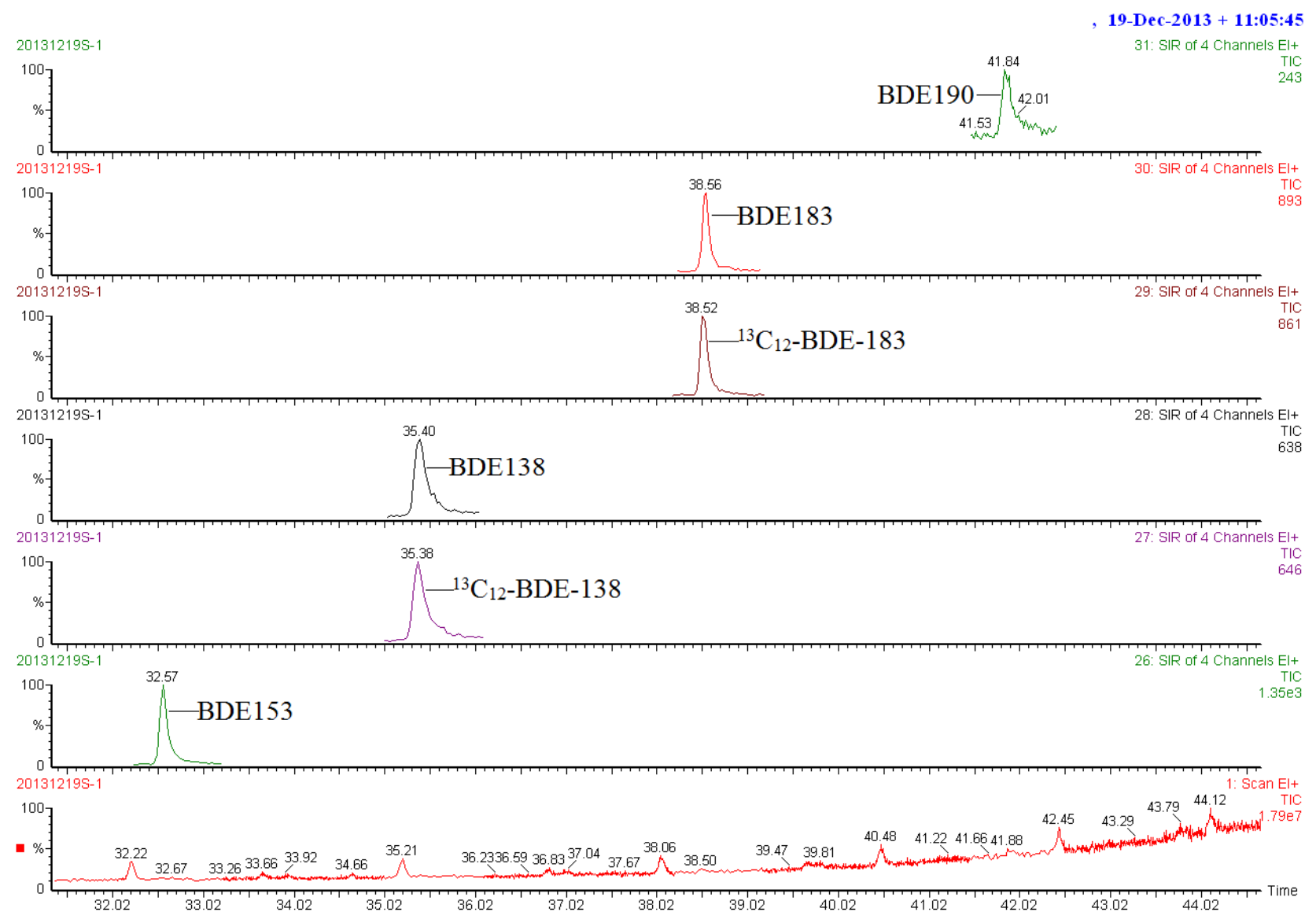

Figure 1. GC-MS chromatogram of a mixed standard solution of MeO-PBDEs, PBDEs and ${ }^{13} C_{12}$-labelled PBDEs (the concentrations of eight MeO-PBDEs, thirteen PBDEs and nine ${ }^{13} C_{12}$-labelled PBDEs are all $100 \mathrm{ng} \mathrm{mL}^{-1}$ )

By the established methods, a large number of channel catfish, crayfish, fish feeds and fishmeal were tested. PBDEs or MeO-PBDEs emerged in 2 of 80 channel catfish, 1 of 80 crayfish, 6 of 60 fish feeds and 4 of 40 fishmeal. Especially,
PBDEs or MeO-PBDEs were tested in fish feeds and fishmeal with a positive rate as high as $10 \%$. Table 5 provided further information.

Table 5. Contents of MeO-PBDEs and PBDEs in channel catfish, crayfish, fish feeds and fishmeal ( $\mu \mathrm{g} \mathrm{kg}^{-1}$ wet weight)

\begin{tabular}{|c|c|c|c|c|c|c|c|c|c|c|c|c|c|c|}
\hline \multirow{2}{*}{ Br No. } & \multirow{2}{*}{ Compound } & \multicolumn{2}{|c|}{ Channel catfish } & \multirow{2}{*}{$\begin{array}{l}\text { Crayfish } \\
\# 1\end{array}$} & \multicolumn{6}{|c|}{ Fish feeds } & \multicolumn{4}{|c|}{ Fishmeal } \\
\hline & & $\# 1$ & $\# 2$ & & $\# 1$ & $\# 2$ & $\# 3$ & $\# 4$ & $\# 5$ & $\# 6$ & $\# 1$ & $\# 2$ & $\# 3$ & $\# 4$ \\
\hline 3 & BDE28 & ND & ND & ND & ND & ND & ND & ND & 4.14 & ND & ND & ND & ND & ND \\
\hline 4 & BDE47 & 2.73 & 2.54 & 4.04 & 6.11 & 4.39 & ND & ND & 5.75 & 9.38 & 6.03 & ND & ND & 11.64 \\
\hline 5 & BDE100 & 4.98 & 3.41 & ND & 12.17 & ND & ND & ND & 9.84 & 8.69 & ND & ND & ND & 8.03 \\
\hline 5 & BDE99 & 4.25 & ND & ND & 9.78 & ND & ND & ND & 11.47 & 8.71 & 12.38 & 11.12 & 8.14 & ND \\
\hline 6 & BDE154 & ND & 2.95 & ND & ND & ND & ND & 10.07 & ND & ND & ND & ND & 16.37 & ND \\
\hline 6 & BDE153 & ND & 3.77 & ND & ND & ND & ND & 12.31 & ND & ND & ND & ND & 10.05 & ND \\
\hline 7 & BDE183 & ND & ND & ND & ND & ND & ND & 23.65 & ND & ND & ND & ND & ND & ND \\
\hline 4 & 2'-MeO-BDE68 & ND & ND & ND & 14.32 & 9.11 & ND & ND & ND & ND & 10.79 & ND & ND & ND \\
\hline 4 & 6-MeO-BDE47 & ND & ND & ND & ND & 15.45 & ND & ND & ND & ND & 8.97 & ND & ND & ND \\
\hline 4 & 4'-MeO-BDE49 & ND & ND & ND & 27.78 & ND & 19.33 & ND & ND & ND & ND & 22.31 & ND & ND \\
\hline
\end{tabular}

ND, lower than LOQ

It was reported that PBDEs and MeO-PBDEs was together present in fish samples at relatively high levels [11-13, 15-16]. Considering that MeO-PBDEs were a novel class of pollutants, contamination of MeO-PBDEs in these reports was more concerned than that of PBDEs in our opinion. Concentrations of 6-MeO-BDE47 and 2'-MeO-BDE68 in fish and shellfish samples from the Mediterranean Sea ranged from less than detection to 12.6 $\mathrm{ng} \mathrm{g}^{-1}$ lipid weight and from less than detection to $2.15 \mathrm{ng} \mathrm{g}^{-1}$ lipid weight, respectively [11]. MeO-PBDEs were also detected in mullet (Mugil cephalus) and sea bass (Dicentrarchus labrax) from Bizerte Lagoon, Tunisia ranging from 6.46 to $798 \mathrm{ng} \mathrm{g}^{-1}$ lipid weight [12]. Moreover, MeO-PBDEs were also detected in fish from the Bohai Sea and the Donghai Sea, China ranging from less than detection to $3.2 \mathrm{ng} \mathrm{g}^{-1}$ dry weight [13]. Recent reports showed that the 
concentrations of MeO-PBDEs ranged from less than detection to $368 \mathrm{pg} \mathrm{g}^{-1}$ lipid weight [15], and concentrations of 6-MeO-BDE47 and 2'-MeO-BDE68 in Japanese common squid collected from East Sea/Japan Sea and Yellow Sea were 40.3 and $99.7 \mathrm{ng} \mathrm{g}^{-1}$ lipid weight and 12.9 and $79.4 \mathrm{ng} \mathrm{g}^{-1}$ lipid weight, respectively [16].

On the basis of those reported results, it is reasonable the $\mathrm{MeO}-\mathrm{PBDEs}$ and PBDEs contamination in channel catfish, crayfish, fish feeds and fishmeal from China should be highly investigated. Although channel catfish and crayfish in this study have been fortunately proved to be $\mathrm{MeO}-\mathrm{PBDEs}$ and PBDEs less positive and in low- $\mu \mathrm{g} \mathrm{kg}$ wet weight, PBDEs or MeO-PBDEs were tested in 6 of 60 fish feeds and 4 of 40 fishmeal with a positive rate as high as $10 \%$ possibly due of complexity of fish feeds and fishmeal production and especially the use of polluted raw material. Considering the direct links between fish feeds and fishmeal safety and safety of channel catfish and crayfish, contaminations and causes of MeO-PBDEs as novel pollutants and PBDEs in channel catfish, crayfish, fish feeds and fishmeal and other aquatic and agricultural products from China still need to be investigated in the future.

\section{Acknowledgements}

This study was supported by the Research Projects of General Administration of Quality Supervision, Inspection and Quarantine of P.R.C (2013IK158 and 2014IK106) and Special Fund for Quality inspection Research in the Public Interest, China (201410059).

\section{References}

[1] C.A. De Wit, "An overview of brominated flame retardants in the environment," Chemosphere 46, pp. 583-624, 2002

[2] I. Watanabe and S.I. Sakai, "Environmental release and behavior of brominated flame retardants," Environ. Int. 29, pp. $665-682,2003$

[3] M. Alaee, P. Arias, A. Sjodin, and A. Bergman, "An overview of commercially used brominated flame retardants, their applications, their use patterns in different countries/regions and possible modes of release," Environ. Int. 29, pp. 683-689, 2003

[4] R. Alcock, A.J. Sweetman, K. Prevedouros, and K.C. Jones, "Understanding levels and trends of BDE-47 in the UK and North America: an assessment of principal reservoirs and source inputs," Environ. Int. 29, pp. 691-698, 2003

[5] B.H. Wilford, T. Harner, J. Zhu, M. Shoeib, and K.C. Jones, "Passive sampling survey of polybrominated diphenyl ether flame retardants in indoor and outdoor air in Ottawa, Canada: implications for sources and exposure," Environ. Sci. Technol. 38 (20), pp. 5312- 5318, 2004

[6] H.M. Stapleton, N.G. Dodder, J.H. Offenberg, M.M. Schantz, and S.A. Wise, "Polybrominated diphenyl ethers in house dust and clothes dryer lint," Environ. Sci. Technol. 39 (4), pp. 925-931, 2005
[7] A. Kirkegaard, A. Bignert, U. Sellstrom, M. Olsson, B. Jansson, and C.A. de Wit, "Polybrominated diphenyl ethers (PBDEs) and their methoxylated derivates in pike from Swedish waters with emphasis on temporal trends, 1967-2000," Environ. Pollut. 130, pp. 187-198, 2004

[8] D. Meironyte, K. Noren, and A. Bergman, "Analysis of polybrominated diphenyl ethers in Swedish human milk. A time-related trend study, 1992-1997," J. Toxicol. Env. Heal. A 58, pp. 101-113, 1999

[9] P. Haglund, D.R. Zook, H.R. Buser, and J. Hu, "Identification and quantification of polybrominated diphenyl ethers and methoxy-polybrominated diphenyl ethers in Baltic biota," Environ. Sci. Technol. 31, pp. 3281-3287, 1997

[10] U. Nordlof, B. Helander, A. Bignert, and L. Asplund, "Levels of brominated flame retardants and methoxylated polybrominated diphenyl ethers in eggs of white-tailed sea eagles breeding in different regions of Sweden," Sci. Total Environ. 409, pp. 238-246, 2010

[11] S. Losada, F.J. Santos, A. Covaci, and M.T. Galceran, "Gas chromatography-ion trap tandem mass spectrometry method for the analysis of methoxylated polybrominated diphenyl ethers in fish," J. Chromatogr. A 1217, pp. 5253-5260, 2010

[12] W.B. Ameur, S.B. Hassine, E. Eljarrat, Y.E. Megdiche, S. Trabelsi, B. Hammami, D. Barcelo, and M.R. Driss, "Polybrominated diphenyl ethers and their methoxylated analogs in mullet (Mugil cephalus) and sea bass (Dicentrarchus labrax) from Bizerte Lagoon, Tunisia," Mar. Environ. Res. 72, pp. 258-264, 2011

[13] J.T. Sun, J.Y. Liu, Q. Liu, G.B. Qu, T. Ruan, and G.B. Jiang, "Sample preparation method for the speciation of polybrominated diphenyl ethers and their methoxylated and hydroxylated analogues in diverse environmental matrices," Talanta 88, pp. 669-676, 2012

[14] K. Lofstrand, X.T. Liu, D. Lindqvist, S. Jensen, and L. Asplund, "Seasonal variations of hydroxylated and methoxylated brominated diphenyl ethers in blue mussels from the Baltic Sea," Chemosphere 84, pp. 527-532, 2011

[15] S. Lacorte, M.G. Ikonomou, and M. Fischer, "A comprehensive gas chromatography coupled to high resolution mass spectrometry based method for the determination of polybrominated diphenyl ethers and their hydroxylated and methoxylated metabolites in environmental samples," J. Chromatogr. A 1217, pp. 337-347, 2010

[16] G.B. Kim and H.M. Stapleton, "PBDEs, methoxylated PBDEs and HBCDs in Japanese common squid (Todarodes pacificus) from Korean offshore waters," Mar. Pollut. Bull. 60, pp. 935-940, 2010

[17] A. Rotander, B. van Bavel, F. Riget, G.A. Auðunsson, A. Polder, G.W. Gabrielsen, G. Víkingsson, B. Mikkelsen, and M. Dam, "Methoxylated polybrominated diphenyl ethers (MeO-PBDEs) are major contributors to the persistent organobromine load in sub-Arctic and Arctic marine mammals, 1986-2009," Sci. Total Environ. 416, pp. 482-489, 2012

[18] P.O. Darnerud, G.S. Eriksen, T. Johannesson, P.B. Larsen, and M. Viluksela, "Polybrominated diphenyl ethers: occurrence, dietary exposure and toxicology," Environ. Health Persp. 109 (Supplement 1), pp. 49-68, 2001 
[19] S.N. Kuriyama, C.E. Talsness, K. Grote, and I. Chahoud, "Developmental exposure to low-dose PBDE-99: Effects on male fertility and neurobehavior in rat offspring," Environ. Health Persp. 113, pp. 149-154, 2005

[20] P. Eriksson, E. Jakobsson, and A. Fredriksson, "Brominated flame retardants: a novel class of developmental neurotoxicants in our environment?" Environ. Health Persp. 109, pp. 903-908, 2001

[21] H. Viberg, A. Fredriksson, and P. Eriksson, "Neonatal exposure to the brominated flame retardant 2,2',4,4',5-pentabromodiphenyl ether causes altered susceptibility in the cholinergic transmitter system in the adult mouse," Toxicol. Sci. 67, pp. 104-107, 2002

[22] H. Viberg, A. Fredriksson, and P. Eriksson, "Neonatal exposure to polybrominated diphenyl ether (PBDE 153) disrupts spontaneous behaviour, impairs learning and memeory, and decreases hippocampal cholinergic receptors in adult mice," Toxicol. Appl. Pharm. 192, pp. 95-106, 2003

[23] T. Zhou, M.M. Taylor, M.J. DeVito, and K.M. Crofton, "Developmental exposure to brominated diphenyl ethers results in thyroid hormone disruption," Toxicol. Sci. 66, pp. 105-116, 2002

[24] I. Branchi, E. Alleva, and L.G. Costa, "Effects of perinatal exposure to a polybrominated diphenyl ether (PBDE-99) on mouse neurobehavioural development," Neurotoxicology 23, pp. 375-384, 2002

[25] I. Branchi, F. Capone, E. Alleva, and L.G. Costa, "Polybrominated diphenyl ethers: neurobehavioral effects following developmental exposure," Neurotoxicology 24, pp. 449-462, 2003

[26] T. Reistad, F. Fonnum, and E. Mariussen, "Neurotoxicity of the pentabrominated diphenyl ether mixture, DE-71, and hexabromocyclododecane (HBCD) in rat cerebellar granule cells in vitro," Arch. Toxicol. 80, pp. 785-796, 2006

[27] F. Madia, G. Giordano, V. Fattori, A. Vitalone, I. Branchi, F. Capone, and L. G. Costa, "Differential in vitro neurotoxicity of the flame retardant PBDE-99 and of the PCB Aroclor 1254 in human astrocytoma cells," Toxicol. Lett. 154, pp. 11-21, 2004
[28] X.Z. Hu, Y. Xu, D.C. Hu, Y. Hui, and F.X. Yang, "Apoptosis induction on human hepatoma cells Hep G2 of decabrominated diphenyl ether (PBDE-209)," Toxicol. Lett. 171, pp. 19-28, 2007

[29] X.Z. Hu, D.C. Hu, and Y. Xu, "Effects of tetrabrominated diphenyl ether and hexabromocyclododecanes in single and complex exposure to hepatoma HepG2 cells," Environ. Toxicol. Phar. 27, pp. 327-337, 2009

[30] Y.H. He, M.B. Murphy, R.M.K. Yu, M.H.W. Lam, M. Hecker, J.P. Giesy, R.S.S. Wu, and P.K.S. Lam, "Effects of 20 PBDE metabolites on steroidogenesis in the H295R cell line," Toxicol. Lett. 176, pp. 230-238, 2008

[31] R.F. Song, Y.H. He, M.B. Murphy, L.W.Y. Yeung, R.M.K. Yu, M.H.W. Lam, P.K.S. Lam, M. Hecker, J.P. Giesy, S.S. WuRudolf, W.B. Zhang, G.Y. Sheng, and J.M. Fu, "Effects of fifteen PBDE metabolites, DE71, DE79 and TBBPA on steroidogenesis in the H295R cell line," Chemosphere 71, pp. 1888-1894, 2008

[32] X.Z. Hu, D.C. Hu, Q. Song, J. Li, P. Wang, and S.F. Guo, "Analysis and occurrences of perfluorinated compounds in agricultural and aquatic products and water from China," J. Liq. Chromatogr. R. T. 34, pp. 2196-2210, 2011

[33] X.Z. Hu, D.C. Hu, Q. Song, J. Li, and P. Wang, "Determinations of hexabromocyclododecane (HBCD) isomers in channel catfish, crayfish, hen eggs and fish feeds from China by isotopic dilution LC-MS/MS," Chemosphere 82, pp. 698-707, 2011

[34] X.Z. Hu, Y. Xu, and A. YEDILER, "Determinations of Residual Furazolidone and Its Metabolite, 3-Amino-2-oxazolidinone (AOZ), in Fish Feeds by HPLC-UV and LC-MS/MS, Respectively,” J. Agric. Food Chem. 55, pp. 1144-1149, 2007

[35] ISO 22032-2006 Water quality-Determination of selected polybrominated diphenyl ethers in sediment and sewage sludge-Method using extraction and gas chromatography/mass spectrometry.

[36] EPA Method 1614 Brominated Diphenyl Ethers in Water Soil, Sediment and Tissue by HRGC/HRMS. 